\title{
Amphibia, Anura, Dicroglossidae, Quasipaa fasciculispina (Inger, 1970): Distribution extension
}

\author{
Yodchaiy Chuaynkern ${ }^{1 *}$, Prateep Duengkae ${ }^{2}$, Pongpitak Sribandit ${ }^{2}$, Komsan Bunchornratana ${ }^{2}$, \\ Chantip Chuaynkern ${ }^{3}$, Nont Khewwan ${ }^{2}$ and Sawang Tipayanukul ${ }^{4}$ \\ 1 Thailand Natural History Museum, National Science Museum, Technopolis. Khlong 5, Khlong Luang, Pathum Thani, 12120 Thailand. \\ 2 Kasetsart University, Faculty of Forestry, Department of Forest Biology. Jatujak, Bangkok, 10900 Thailand. \\ 3 Khon Kaen University, Faculty of Science, Department of Biology. Muang, Khon Kaen, 40002 Thailand. \\ 4 Khlong Kreua Wai Wildlife Sanctuary. P.O. Box 9, Makham, Chanthaburi, 22150 Thailand. \\ * Corresponding author. E-mail: ychuaynkern@yahoo.com
}

\begin{abstract}
The current work presents a new locality for Quasipaa fasciculispina (Inger, 1970) documenting the first provincial record based on voucher specimens for Trat Province (eastern Thailand). Its geographical distribution is reviewed and a recent distribution map in Thailand is presented.
\end{abstract}

As a result of Ohler and Dubois (2006), a new working taxonomy of the tribe Paini was proposed. The genus Quasipaa Dubois, 1992 currently contains 10 described species [Q. acathophora Dubois and Ohler, 2009, Q. boulengeri (Günther, 1889), Q. courtoisi (Angel, 1922), Q. exilispinosa ( $\mathrm{Liu}$ and $\mathrm{Hu}, 1975), Q$. fasciculispina (Inger, 1970), Q. jiulongensis (Huang and Liu, 1985), Q. shini (Ahl, 1930), Q. spinosa (David, 1975), Q. verrucospinosa (Bourret, 1937), and Q. yei (Chen, Qu and Jiang, 2002)] which are distributed across southern and southwestern China to central Vietnam, eastern Thailand and southwestern Cambodia (Frost 2010). Q. fasciculispina was originally described as Rana fasciculispina based on an adult male (holotype, National Center for Reference Collections of Thailand, number 513-1385) and a female (paratype, Field Museum of Natural History 171309); both collected from "Khao Soi Dao, Changwat Chantaburi, Thailand" (currently Khao Soi Dao Wildlife Sanctuary, Chanthaburi Province, Thailand) by Inger (1970). This species has been recently found to be endemic to the Thai-Cambodian border according to various published works (e.g., Inger 1970; Ohler et al. 2002; Chan-ard 2003; Nabhitabhata et al. 2004; Inthara et al. 2005, 2009; Nabhitabhata and Chanard 2005; Stuart and Emmett 2006; Grismer et al. 2008; Thy et al. 2010). Its global status (see van Dijk and Swan 2004) is identified as Vulnerable (VU) because its extent of occurrence is less than 20,000 square $\mathrm{km}$. The distribution is severely fragmented and the population is continuing to decline because of decline in the extent and quality of its forest habitat in Cambodia and Thailand. Given the local status in Thailand, Nabhitabhata and Chan-ard (2005) list its status as VU. This species, both frogs and tadpoles, is illegally collected for food (Inthara et al. 2009).

Supaprom and Baimai (2004) report that the mitotic karyotype consist of 8 metacentric (M) and 5 submetacentric (SM) pairs. The group of large chromosomes comprises $2 \mathrm{M}$ (nos. 1 and 5) and $3 \mathrm{SM}$ (nos. 2,3 and 4) while the group of small chromosomes includes
$6 \mathrm{M}$ (nos. 6, 7, 8, 10, 11 and 12) and 2 SM (nos. 9 and 13). A secondary constriction is clearly observed in the middle of the short arm of chromosomes no. 6 (6 p.). Its tadpole was figured by Inthara et al. (2005) and subsequently larval external and buccal morphologies were described by Inthara et al. (2009).

In the current study, a series of 11 juvenile specimens (THNHM 18238-18248, unsexed, SVL 25.83-75.93 $\mathrm{mm})$ were collected from Huay Khao Plu (12 $23^{\prime} 29^{\prime \prime}$ $\mathrm{N}, 102^{\circ} 40^{\prime} 51^{\prime \prime} \mathrm{E}$ at an elevation of $120 \mathrm{msl}$ ), near the Trat Agroforestry Research Station (TARS; coordinate $12^{\circ} 23^{\prime} 35^{\prime \prime} \mathrm{N}, 102^{\circ} 40^{\prime} 6^{\prime \prime} \mathrm{E}$ at an elevation of $40 \mathrm{msl}$ ), Muang Trat District, Trat Province on 19 March 2010. These specimens were catalogued and deposited in the collection of the Thailand Natural History Museum, Pathum Thani (Thailand). These frogs (Figure 1) were assigned to $Q$. fasciculispina as its morphological characters conformed to Inger's (1970) description. Quasipaa fasciculispina is characterized by the following characters: 1) back with numerous short, thick ridges, none as long as diameter of eye, interspersed with circular warts and 2) webbing complete. During the survey, no adult frogs were observed.

In Khlong Kreua Wai Wildlife Sanctuary (Chanthaburi Province), photographs of live Quasipaa fasciculispina were taken from the sanctuary by a forest ranger on 23 January 2009 (Figure 1 right) and 3 February 2009 (Figure 1 upper left). After photography, the frogs were released at the capture sites. The adult male possessed the secondary sex characters conforming to Inger (1970) such as: forearm enlarged, throat with circular whitish tubercles bearing strong black spines in each tubercle.

Prior to this study, the distribution of Quasipaa fasciculispina in Thailand was reported from the provinces of Chanthaburi [Khao Chamao-Khao Wong National Park (Forest Biology Department unpublished data), Khao Kitchakut National Park (Noikotr and Lauhachinda 2002; Chan-ard 2003; Nabhitabhata et al. 2004; Inthara et al. 2005; Nabhitabhata and Chan-ard 2005), Khao Sip 

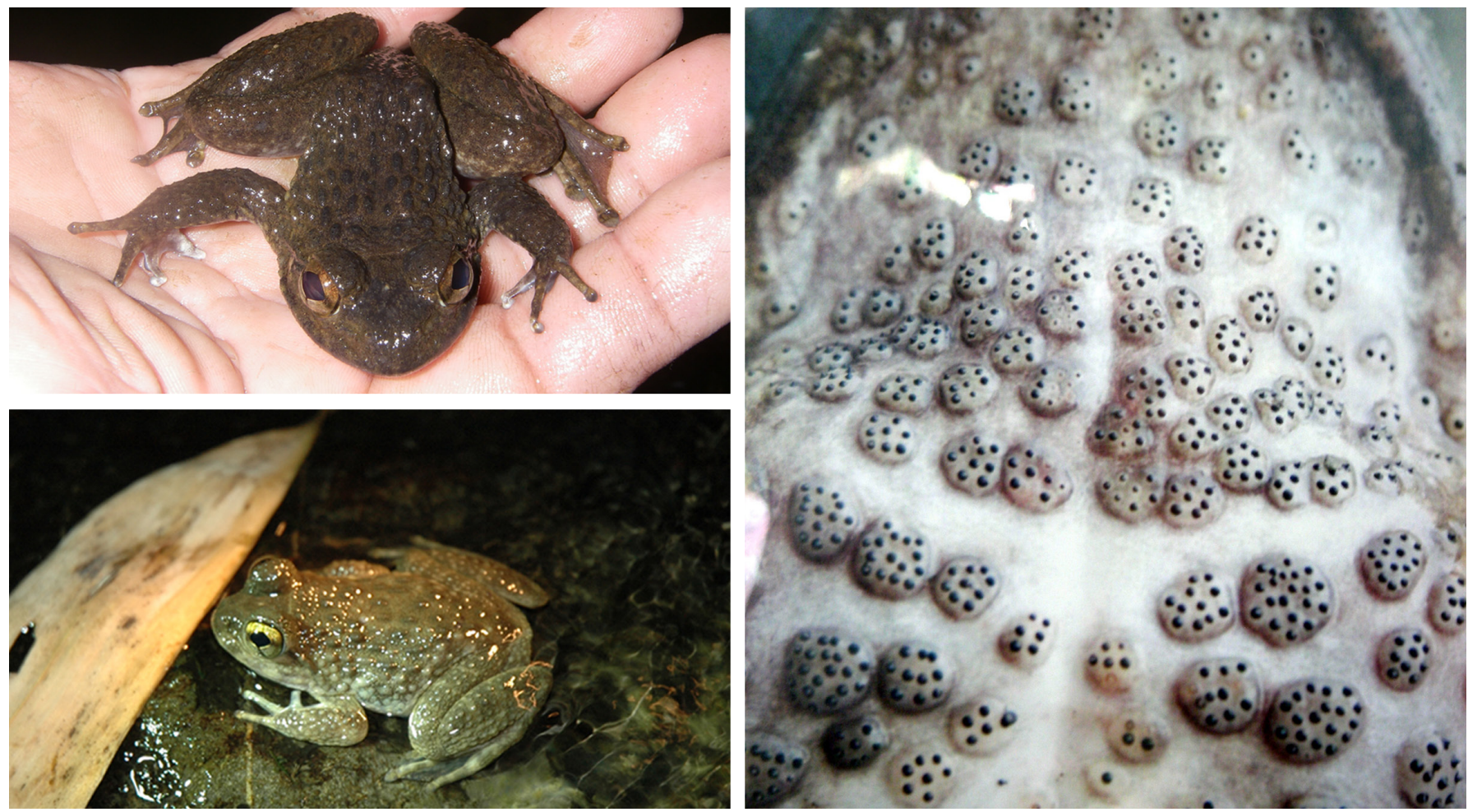

Wai Wildlife Sanctuary, Chanthaburi Province); bottom left (Huay Khao Plu, Muang Trat District, Trat Province); and right (cluster of spines on chest and breast of adult male in breeding season).

Ha Chan National Park (Danaisawat et al. 2010), Khao Soi Dao Wildlife Sanctuary (Inger 1970; Chan-ard 2003; Nabhitabhata et al. 2004; Nabhitabhata and Chan-ard 2005; Inthara et al. 2009), and Namtok Phliew Naitonal Park (Chan-ard 2003, as Khao Sra Baab )] and Trat [Bo Rai District (Inthara et al. 2005)]. The locality lying southward from the type locality (Khao Soi Dao) is "Khao Sra Baab" according to Chan-ard (2003), but neither voucher specimens nor photographs are provided in this work. Although Chan-ard (2003) provides a live photo of this species, the photograph did not provide the locality of the frog. A herpetological study in Namtok Phliew National Park was recently conducted by Narongrit Sukprakarn, but the research failed to document $Q$. fasciculispina in the national park (see Sukprakarn and Nabhitabhata 2003). Moreover, the distribution in Thailand is usually claimed to range from eastern Thailand extending to the Cardamom Mountains in western Cambodia (see Chan-ard 2003). However, the record indicates that the occurrence of this species in Trat Province was in Inthara et al. (2005). Unfortunately, they did not refer to voucher specimens. Although several studies were conducted in Trat Province (e.g., Smith and Kloss 1915; Taylor and Elbel 1958; Taylor 1962; Ha-Ngam et al. 2006) unfortunately, they failed to document $Q$. fasciculispina. Therefore, the current work documents the first provincial record (based on voucher specimens) for the province, and its geographical distribution of the species in Thailand is now extended southward to Trat Province. The collected site is ca. 150 $\mathrm{km}$ southeastern from the type locality (Figure 2). The area is a secondary forest which was been previously logged.

Although knowledge about the evolution, systematics and taxonomy of painid frogs has substantially increased (see Jiang et al. 2005; Frost et al. 2006; Ohler and Dubois 2006; Inthara et al. 2009), there are still gaps or

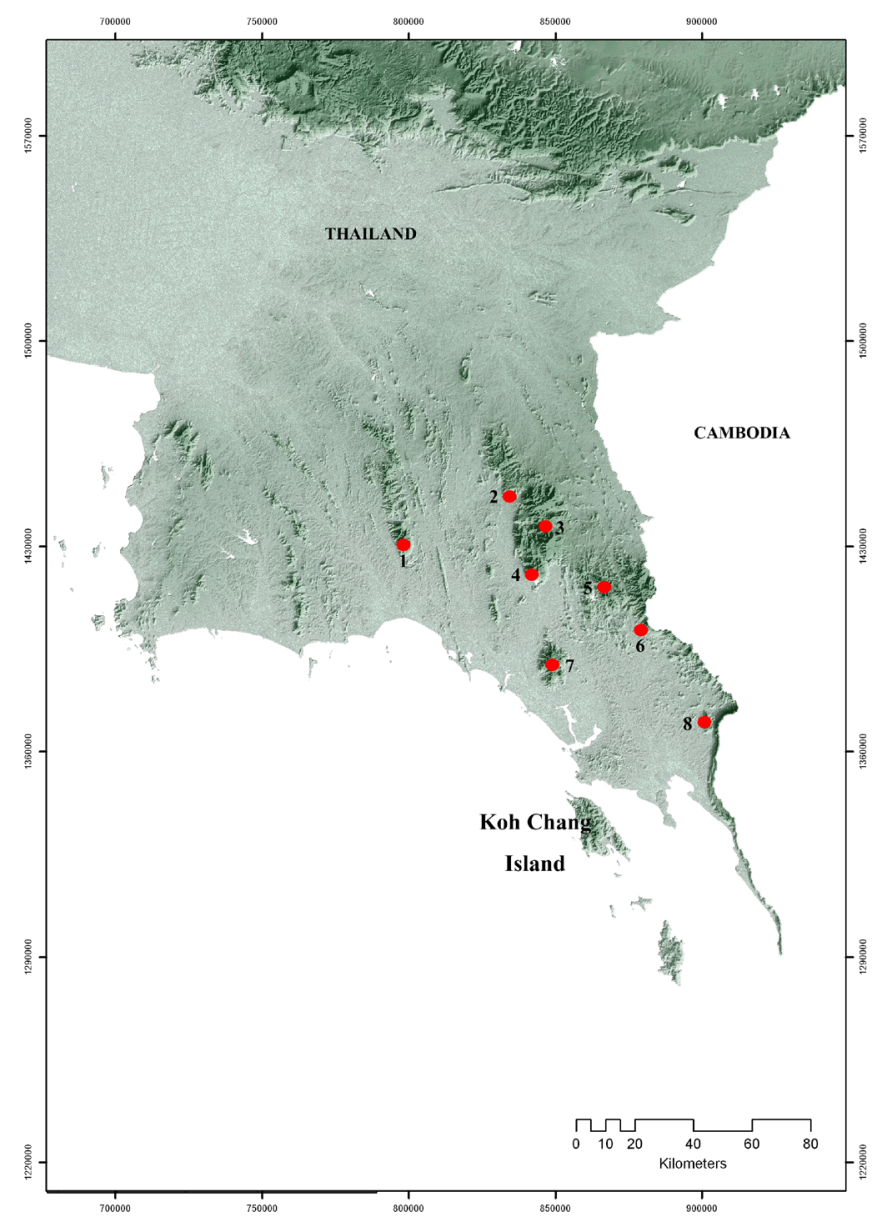

FIGURE 2. Distribution of Quasipaa fasciculispina in Thailand. 1, Khao Chamao-Khao Wong National Park (Chanthaburi Province); 2, Khao Sip Ha Chan National Park (Chanthaburi Province); 3, Khao Soi Dao Wildlife Sanctuary (Chanthaburi Province); 4, Khao Kitchakut National Park (Chanthaburi Province); 5, Khlong Kreua Wai Wildlife Sanctuary (Chanthaburi Province); 6, Bo Rai District (Trat Province); 7, Namtok Phliew National Park (Chanthaburi Province); and 8, Muang District (Trat Province). 
insufficiencies in other basic knowledge. These gaps might be due to the members of this group inhabiting a specific microhabitat in swift streams (Bourret 1937; Liu 1950), usually in montane areas. The members of Quasipaa are considered as rare species. The 10 species of Quasipaa are listed in four categories of the IUCN Red List of Threatened species (IUCN 2010): Endangered (one species, $Q$. boulengeri), Vulnerable (five species, Q. exilispinosa, $Q$. fasciculispina, $Q$. jiulongensis, $Q$. shini and Q. spinosa), Near Threatened (one species, $Q$. verrucospinosa), Data Deficient (one species, Q. yei). Two species ( $Q$. acathophora and Q. courtoisi) are not in the list. Thus, voucher specimens are quite rare in natural history collections and might inadequately support the study of this group in various disciplines.

The global and local status of Quasipaa fasciculispina have the same VU evaluation according to two published works (Nabhitabhata and Chan-ard 2005; Stuart et al. 2008) and IUCN (2010). The species is protected under the WARPA law of Thailand. The species is found in protected areas (such as national parks and wildlife sanctuaries etc.) where there is strong enforcement to its conservation. However, illegal consumption still occurs and more intensive conservation strategies are needed. Further study is needed to explore the distribution range in neighboring areas. Probably additional undiscovered populations exist in the streams of a small range of mountains along the Thai-Cambodian border and also in the mountain on an island such as Koh Chang (southwestern of locality 5 in Figure 2). Other disciplines are recommended to further research: exploitation pressure, status evaluation, and frog propagation.

ACKNOWLEDGMENTS: We are grateful to our institutes for facilitating this study: National Science Museum (Pathum Thani, Thailand), Kasetsart University (Bangkok, Thailand), Trat Agroforestry Research Station (Trat, Thailand), Khon Kaen University (Khon Kaen, Thailand), and Khlong Kreua Wai Wildlife Sanctuary (Chanthaburi, Thailand). The field survey was conducted during the project "Inventory and Assessment of Endemic and Threatened Species of Bio-resources for Sustainable Utilization in Eastern of Thailand" and fully supported by funding from the Kasetsart University Research and Development Institute to PD. The following people are thanked for their assistance during the field survey: Nantasak Pinkaew, Atchara Teerawatananon, Chatchai Ngernsaengsaruay, Aingorn Chaiyes, Wongphan Promwong, Nongnoot Anuraktrakoon and Paweena Wessapak. Jeerawat Jaisillthum is thanked for assistance in the first draft. Our special thanks go to Robert H. Orr for editing the second draft.

\section{Literature Cited}

Bourret, R. 1937. Notes herétologique sur l'Indochine française. Xiv. Les batracien de la Collection du Laboratoire des Sciences naturelles de l'Université. Annexe au Bulletin Géneral de l'Instruction Pulbique 1937: 1-56.

Chan-ard, T. 2003. A Photographic Guide to Amphibians in Thailand. Bangkok: Darnsutha Press Co. Ltd. 174 p.

Danaisawat, P., A.-O. Pradatsundarasan and W. Khonsue. 2010. Morphological character of some tadpole from Khao Sip Ha Chan proposed national park, Chanthaburi Province. Journal of Wildlife in Thailand. 17: 64-103.

Frost, D.R. 2010. Amphibian Species of the World: an Online Reference. Version 5.4 (8 April, 2010). Electronic Database accessible at http:// research.amnh.org/vz/herpetology/amphibia/American Museum of Natural History, New York, USA. Captured on 15 October 2010.

Frost, D.R., T. Grant, J. Faivovich, R.H. Bain, A. Haas, C.F.B. Haddad, R.O. de Sa, A. Channing, M. Wilkinson, S.C. Donnellan, C.J. Raxworthy, J.A. Campbell, B.L. Blotto, P. Moler, R.C. Drewes, R.A. Nussbaum, J.D. Lynch, D.M. Green and W.C. Wheeler. 2006. The amphibian tree of life. Bulletin of the American Museum of Natural History 297: 1-370.
Grismer, L.L., T. Neang, T. Chav, P.L. Wood, Jr., J.R. Oaks, J. Holden, J.L. Grismer, T.R. Szutz and T.M. Youmans. 2008. Additional amphibians and reptiles from the Phnom Samkos Wildlife Sanctuary in northwestern Cardamom Mountains, Cambodia, with comments on their taxonomy and the discovery of three new species. The Raffles Bulletin of Zoology 56: 161-175.

Ha-ngam, P., P. Duengkae and C. Wacharinrat. 2006. A herpetological survey of Trat Agroforestry Research Station, Trat Province. Journal of Wildlife in Thailand 13: 190-200.

Inger, R.F. 1970. A new species of frog of the genus Rana from Thailand. Fieldiana: Zoology 51: 169-174.

Inthara, C., V. Lauhachinda, J. Nabhitabhata, Y. Chuaynkern and P. Kumtong. 2005. Mouth part structures and distribution of some tadpoles from Thailand. The Thailand Natural History Museum Journal 1: 55-78.

Inthara, C., Y. Chuaynkern, P. Duengkae and S. Grosjean. 2009. The tadpole of Quasipaa fusciculispina (Inger, 1970) from southeastern Thailand, with the description of its buccal anatomy. Alytes 26: 86-96.

IUCN. 2010. IUCN Red List of Threatened Species. Version 2010.2. Electronic Database accessible at http://www.iucnredlist.org. Captured on 29 June 2010.

Jiang, J., A. Dubois, A. Ohler, A. Tillier, X. Chen, F. Xie and M. Stöck. 2005. Phylogenetic relationships of the tribe Paini (Amphibia, Anura, Ranidae) based on partial sequences of mitochondrial $12 \mathrm{~s}$ and $16 \mathrm{~s}$ rRNA genes. Zoological Science 22: 353-362.

Liu, C.C. 1950. Amphibians of western China. Fieldiana: Zoology Memmores 2: 1-400.

Nabhitabhata, J. and T. Chan-ard. 2005. Thai Red List Data: Mammals, Reptiles and Amphibians. Bangkok: Office of Natural Resources and Environmental Policy and Planning, $234 \mathrm{p}$.

Nabhitabhata, J., T. Chan-ard and Y. Chuaynkern. 2004. Checklist of Amphibians and Reptiles in Thailand. Bangkok: Office of Natural Resources and Environmental Policy and Planning, $152 \mathrm{p}$.

Noikotr, K. and V. Lauhachinda. 2002. Diversity of anurans in Khaokitchakut, Chanthaburi Province. Journal of Wildlife in Thailand 10: 7-16.

Ohler, A. and A. Dubois. 2006. Phylogenetic relationships and generic taxonomy of the tribe Paini (Amphibia, Anura, Ranidae, Dicroglossinae), with diagnoses of two new genera. Zoosystema 28: 769-784.

Ohler, A., S.R. Swan and J.C. Daltry. 2002. A recent survey of the amphibian fauna of the Cardamom Mountains, Southwest Cambodia with descriptions of three new species. The Raffles Bulletin of Zoology 50: 465-481.

Smith, M.A. and B.K. Kloss. 1915. On reptiles and batrachians from the Coast and islands of South-East Siam. Natural History Bulletin of the Siam Society 1: 237-249.

Stuart, B.L. and D.A. Emmett. 2006. A collection of amphibians and reptiles from the Cardamom Mountains, southwestern Cambodia. Fieldiana: Zoology, N.S. 109: 1-11.

Stuart, S., M. Hoffmann, J. Chanson, N. Cox, R. Berridge, P. Ramani and B. Young, B. (ed.). 2008. Threatened Amphibians of the World. Barcelona: Lynx Edicions. 758 p.

Sukprakarn, N. and J. Nabhitabhata. 2003. Species diversity and habitats of amphibians and reptiles at Namtok Phliu National Park, Chanthaburi Province; p. 235-244 In V. Baimai and R. Tantalakha (ed). BRT Research Report 2003. Bangkok: Chuan Printing Press Ltd. Part [In Thai with an English abstract].

Supaprom, T. and V. Baimai. 2004. Karyotypes of ten species of ranid frogs (Anura: Ranidae) from Thailand. Amphibia-Reptilia 25: 104-111.

Taylor, E.H. 1962. The amphibians fauna of Thailand. The University of Kansas Science Bulletin 43: 265-599.

Taylor, E.H. and R.E. Elbel. 1958. Contribution to the herpetology of Thailand. The University of Kansas Science Bulletin 38: 1033-1186.

Thy, N., L.L. Grismer, C.K. Onn, J.L. Grismer, P.L. Wood Jr. and T.M. Youmans. 2010. First report on the herpetofauna of Dalai Mountain in Phnom Samkos Wildlife Sanctuary, southwestern Cardamom Mountains, Cambodia. Cambodian Journal of Natural History 2010: 127-143.

van Dijk, P.P. and S. Swan. 2004. Quasipaa fasciculispina. In IUCN 2010. IUCN Red List of Threatened Species. Version 2010.1. Electronic Database accessible at http://www.iucnredlist.org. Captured on 08 April 2010.

RECEIVED: October 2010

LAST REVISED: February 2011

ACCEPTED: February 2011

Published ONLINE: March 2011

EDITORIAL RESPONSIBILITY: Marcelo N. de C. Kokubum 